Supporting Information for:

\title{
Temperature-induced aggregation in portlandite suspensions
}

Sharu Bhagavathi Kandy $\left({ }^{a}, b\right)$, Iman Mehdipour $\left({ }^{a, b}\right)$, Narayanan Neithalath (c), Mathieu Bauchy

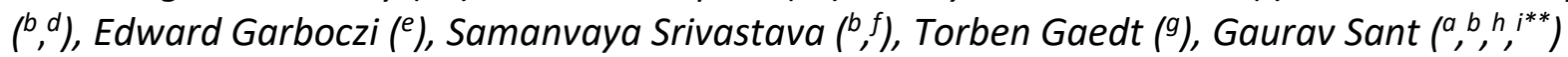

Number of pages: 8 (including the title page)

Number of figures: 9

\footnotetext{
a Laboratory for the Chemistry of Construction Materials $\left(\mathrm{LC}^{2}\right)$, Department of Civil and Environmental Engineering, University of California, Los Angeles, CA 90095, USA

${ }^{b}$ Institute for Carbon Management (ICM), University of California, Los Angeles, CA 90095, USA

' School of Sustainable Engineering and the Built Environment, Arizona State University, Tempe, AZ 86587, USA

d Laboratory for the Physics of AmoRphous and Inorganic Solids (PARISlab), Department of Civil and Environmental Engineering, University of California, Los Angeles, CA 90095, USA

e Applied Chemicals and Materials Division, Material Measurement Laboratory, National Institute of Standards and Technology, Boulder, CO 80305, USA

${ }^{f}$ Department of Chemical and Biomolecular Engineering, University of California, Los Angeles, CA 90095, USA

${ }^{g}$ Department of Chemistry, Technische Universität München, Lehrstuhl für Bauchemie, Lichtenbergstrasse 4, 85747 Garching, Germany

${ }^{\mathrm{h}}$ Department of Materials Science and Engineering, University of California, Los Angeles, CA 90095, USA

i California Nanosystems Institute (CNSI), University of California, Los Angeles, CA 90095, USA

${ }^{* *}$ Corresponding author: G. Sant, Phone (310) 206-3084,Email: gsant@ucla.edu
} 


\section{(A) Particle Size Distribution}

The particle size distributions of $\mathrm{Ca}(\mathrm{OH})_{2}$ and quartz particles were determined by static light scattering (Figure S1a). The scanning and transmission electron micrographs illustrate the aggregate morphology of portlandite particulates (standard hydrated lime, $d_{50}=4.6 \mu \mathrm{m} \pm 0.1$ $\mu \mathrm{m})$ and the primary particle sizes. To prepare a sample for transmission electron microscopy investigation, a dilute suspension of portlandite particulates was dispersed in isopropyl alcohol via ultrasonication and a drop of dispersion was deposited on to a TEM grid and dried thereafter.

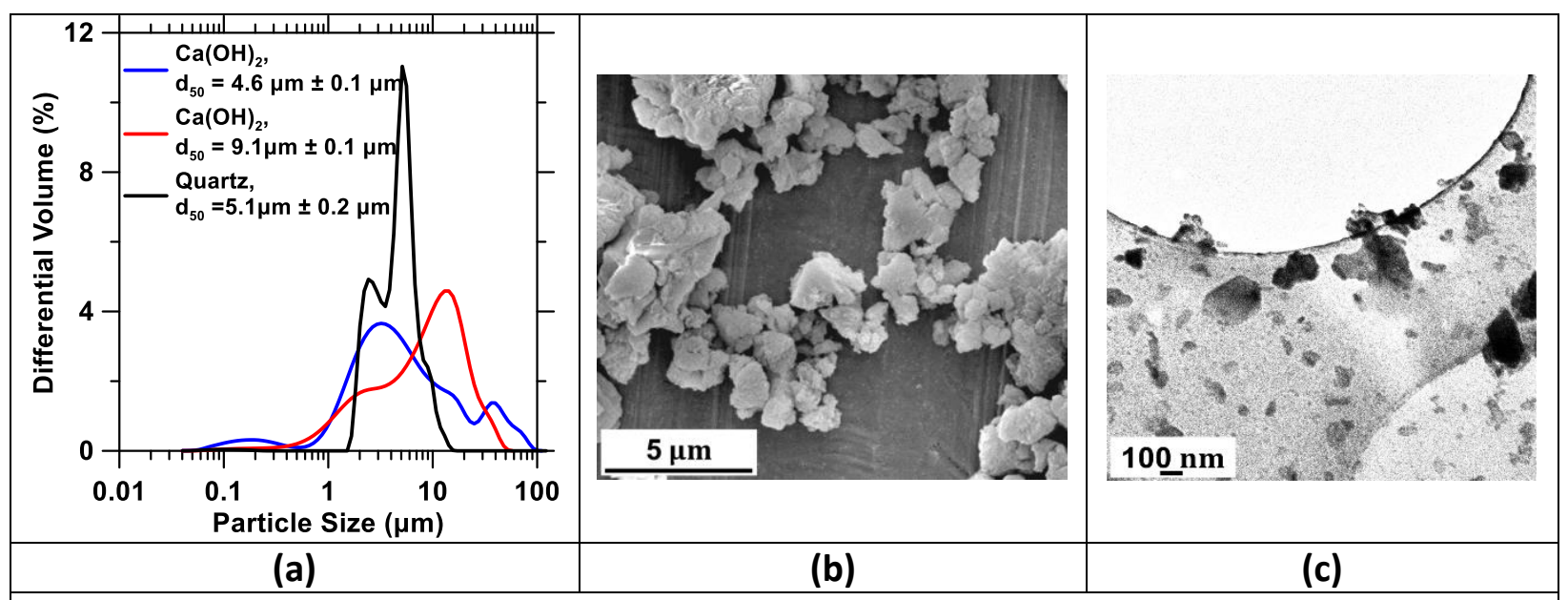

Figure S1: (a) Particle size distributions of $\mathrm{Ca}(\mathrm{OH})_{2}$ and quartz particles as determined using static light scattering. Here, the error represents the standard deviation based on three replicate measurements; (b) SEM micrograph of portlandite particulates (standard hydrated lime) showing the morphology of particle aggregates; (c) TEM micrograph of portlandite particulates depicting primary particle size. 


\section{Viscosity versus shear rate curves of $\mathrm{Ca}(\mathrm{OH})_{2}$ suspensions}

Figure $\mathrm{S} 2$ shows the apparent viscosity trends of $\mathrm{Ca}(\mathrm{OH})_{2}$ suspensions (for $\mathrm{d}_{50}=9.1 \mu \mathrm{m}$ ) at a shear rate $\dot{\gamma}=1 \mathrm{~s}^{-1}$ at $25^{\circ} \mathrm{C}, 50^{\circ} \mathrm{C}$ and $75^{\circ} \mathrm{C}$ as a function of the solid volume fraction.

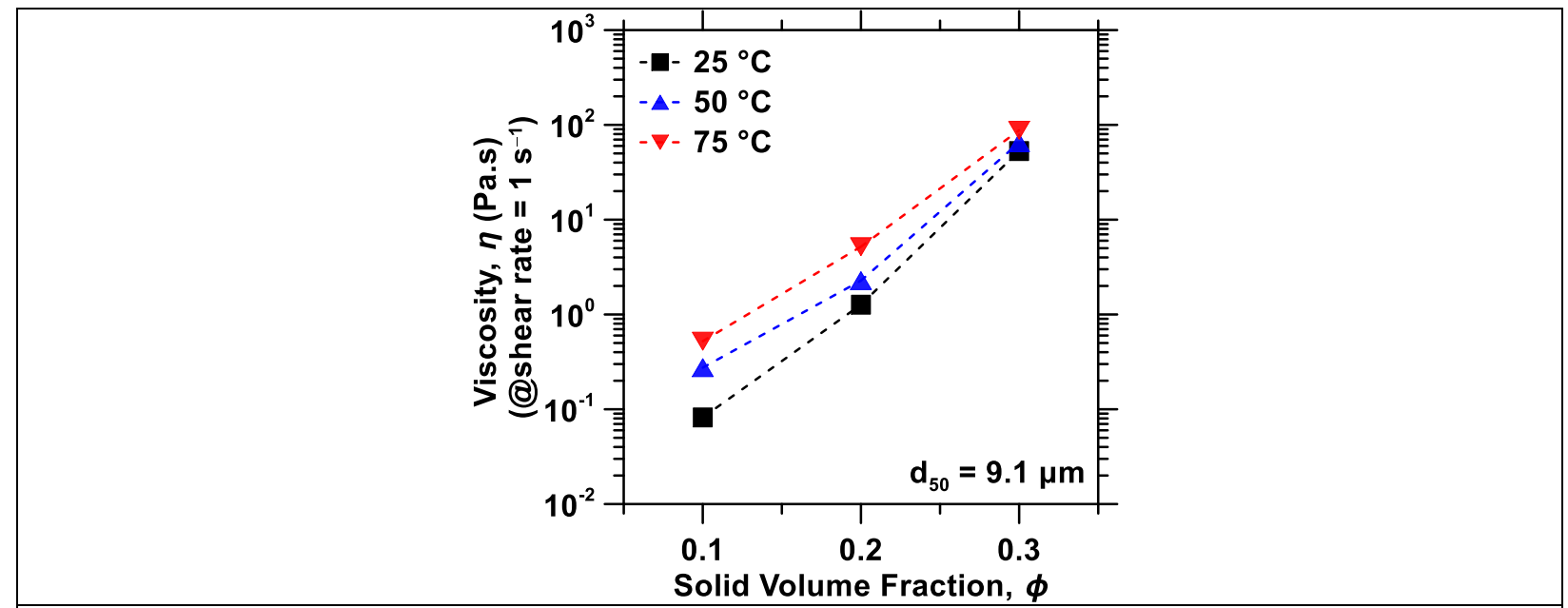

Figure S2: The apparent viscosity trends of $\mathrm{Ca}(\mathrm{OH})_{2}$ suspensions (for $\mathrm{d}_{50}=9.1 \mu \mathrm{m}$ ) at a shear rate $\dot{\gamma}=1 \mathrm{~s}^{-1}$ as a function of the solid volume fraction at $25^{\circ} \mathrm{C}, 50^{\circ} \mathrm{C}$ and $75^{\circ} \mathrm{C}$. Based on three replicate measurements, the uncertainty in the measured apparent viscosity data is $<$ $12 \%$.

Figure S3 shows the representative flow curves at different temperatures obtained through shear sweep for $\mathrm{Ca}(\mathrm{OH})_{2}$ suspensions $\left(\mathrm{d}_{50}=4.6 \mu \mathrm{m}\right)$ with two different particle sizes. The apparent viscosity is expressed as a function of the Mason number, which indicates the strength of shear deformation relative to the strength of attraction between contacting particles in the aggregates. Flow curves were procured at three different temperatures ( $T=25$ ${ }^{\circ} \mathrm{C} \pm 0.1{ }^{\circ} \mathrm{C}, T=50^{\circ} \mathrm{C} \pm 0.1{ }^{\circ} \mathrm{C}$ and $T=75^{\circ} \mathrm{C} \pm 0.1{ }^{\circ} \mathrm{C}$ ) for suspensions with three different volume fractions $(\phi=0.1, \phi=0.2$ and $\phi=0.3)$. All the suspensions exhibit shear-thinning behaviour and in line with the expectation, the apparent viscosity increases with $\phi$. Further, the viscosity of suspensions increases with the increase in temperature over the studied range of shear rate. However, the extent of shear-thinning moderately increases with the suspension temperature suggesting the rupture of temperature-induced aggregates with increasing Mason number.

Figure S4 illustrates the Arrhenius plots of viscosity, $\ln (\eta)$ vs $1 / T$ for different shear rates. This temperature-dependent viscosity data of $\mathrm{Ca}(\mathrm{OH})_{2}$ suspensions fit well with the Arrhenius law and the activation energy of viscous flow, $E_{a}$ (a measure of the temperature dependence of viscosity) was estimated from the slope of the linear fit. 


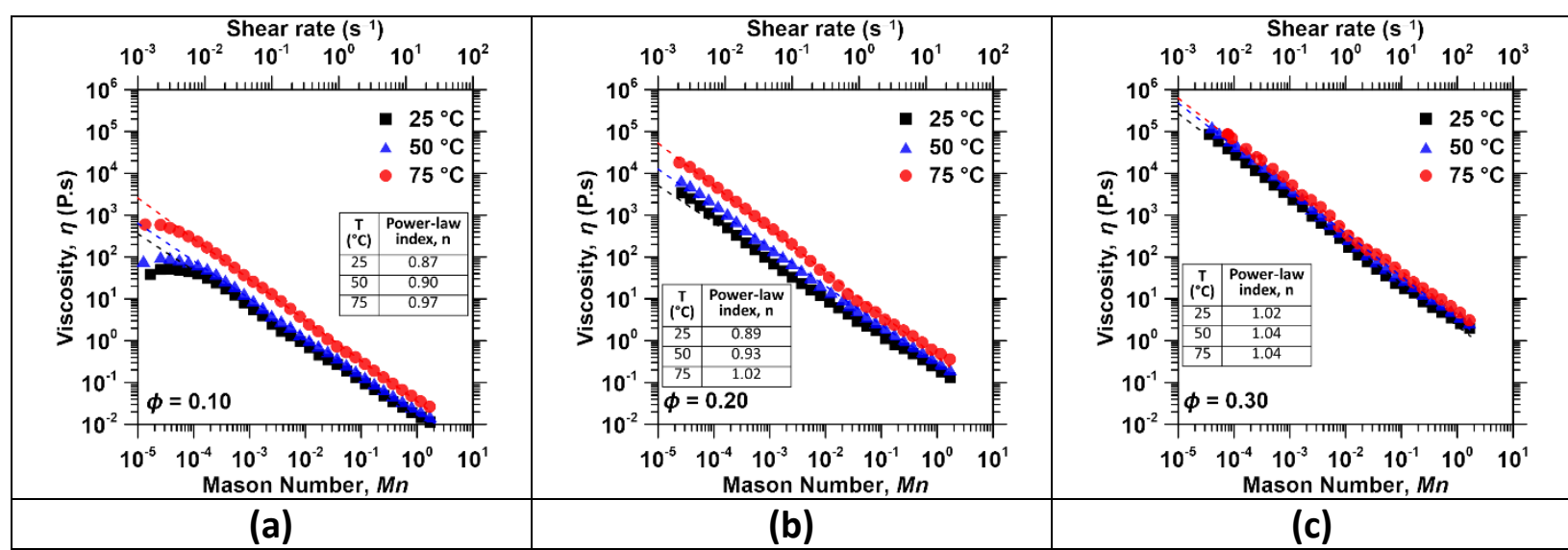

Figure S3: Representative flow curves of $\mathrm{Ca}(\mathrm{OH})_{2}$ suspensions $\left(d_{50}=4.6 \mu \mathrm{m}\right)$ represented in terms of viscosity vs. Mason number at varying solid volume fractions at $\mathrm{T}=25^{\circ} \mathrm{C} \pm 0.1{ }^{\circ} \mathrm{C}, 50$

${ }^{\circ} \mathrm{C} \pm 0.1{ }^{\circ} \mathrm{C}$, and $75{ }^{\circ} \mathrm{C} \pm 0.1{ }^{\circ} \mathrm{C}$ obtained through shear rate sweeps. The inset table lists the power-law indices indicating the extent of shear-thinning at different suspension temperatures. The shear-rate sweep measurements were replicated thrice and the uncertainty in the measured apparent viscosity data is $<12 \%$.

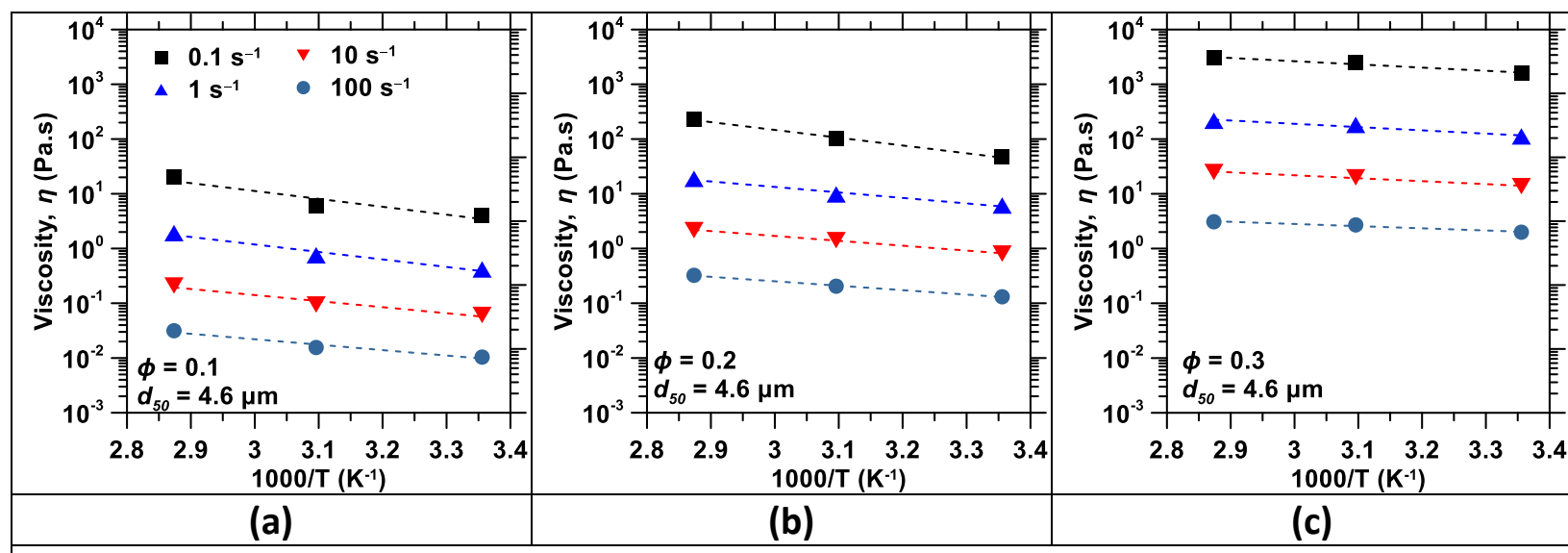

Figure S4: Arrhenius plots of suspension viscosity for $\mathrm{Ca}(\mathrm{OH})_{2}$ suspensions $\left(d_{50}=4.6 \mu \mathrm{m}\right)$ for varying solid volume fractions $\phi=0.1,0.2$ and 0.3 . The Arrhenius plots were generated for apparent viscosities corresponding to different shear rates $\left(0.1 \mathrm{~s}^{-1}, 1 \mathrm{~s}^{-1}, 10 \mathrm{~s}^{-1}\right.$, and $\left.100 \mathrm{~s}^{-1}\right)$. Activation energy values are estimated from the slopes of Arrhenius plots.

Figure S5 depicts the influence of shear rate on temperature-dependent viscous flow. The activation energy of viscous flow decreases with increasing shear rate, suggesting that the temperature dependence of viscosity diminishes with increasing shear rate. 


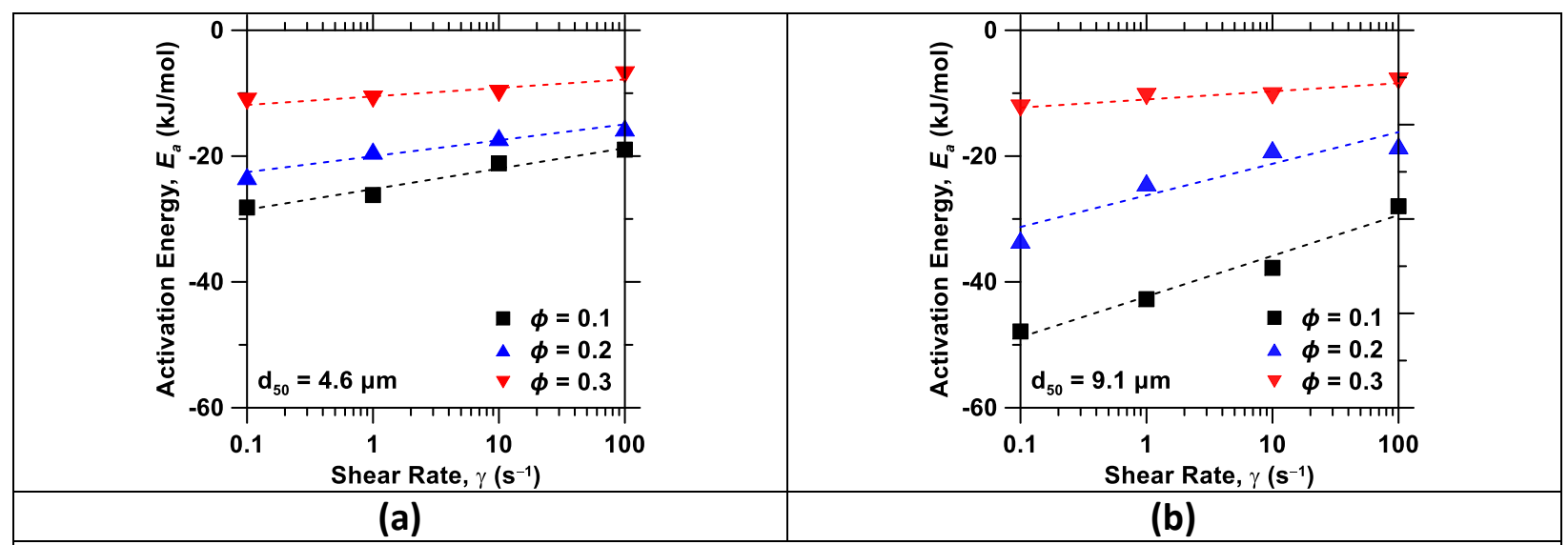

Figure S5: The variations in viscous activation energy as a function of applied shear rate for $\mathrm{Ca}(\mathrm{OH})_{2}$ suspensions with different solid volume fractions for $(a) d_{50}=4.6 \mu \mathrm{m} ;(b) d_{50}=9.1 \mu \mathrm{m}$.

\section{(B) Temperature dependence of linear viscoelastic modulus and crossover energy}

Figure S6a illustrates the amplitude sweep curves at different temperatures in terms of dynamic elastic and loss moduli $\left(G^{\prime}\right.$ and $\left.G^{\prime \prime}\right)$ for $\mathrm{Ca}(\mathrm{OH})_{2}$ suspensions $(\phi=0.1)$. The results indicate that linear elastic modulus (i.e., $G^{\prime}$ plateau in the linear viscoelastic region) increases with the increase in temperature. Further, the crossover energy of suspensions was estimated at different temperatures to assess the impact of temperature on suspension structure. Figure S6b shows the variation in crossover energy with temperature for $\mathrm{Ca}(\mathrm{OH})_{2}$ suspensions. The crossover energy increases with the increase in temperature, suggesting that stronger aggregates with greater strength of links between flocs are present in the suspension with increasing temperature, which requires higher energy to disrupt the overall suspension structure.

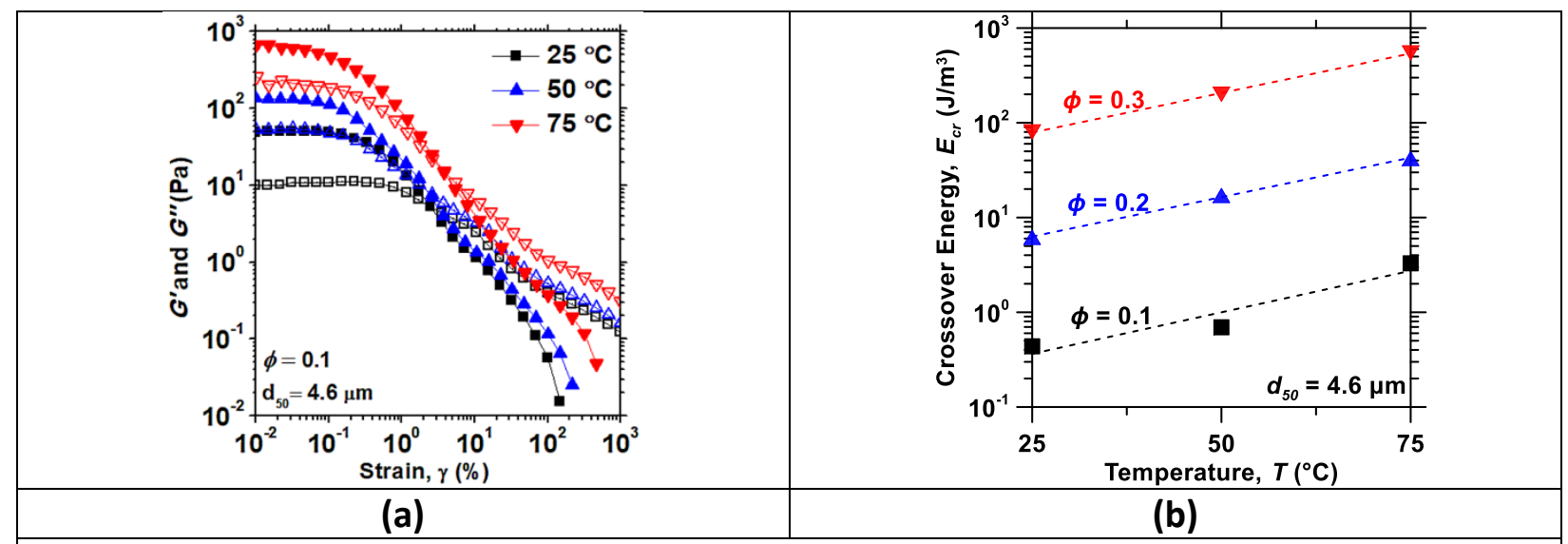

Figure S6: (a) Amplitude sweep curves illustrating the variations in storage modulus $\left(G^{\prime}\right)$ and loss modulus $\left(G^{\prime \prime}\right)$ of $\mathrm{Ca}(\mathrm{OH})_{2}$ suspensions $\left(\mathrm{d}_{50}=4.6 \mu \mathrm{m}\right)$ for different temperatures. The filled symbols denote $G^{\prime}$ and open symbols denote $G^{\prime \prime}$. (b) Variation in crossover energy of $\mathrm{Ca}(\mathrm{OH})_{2}$ suspensions $\left(d_{50}=4.6 \mu \mathrm{m}\right)$ as a function of temperature. Based on three replicate measurements, the highest uncertainty observed was $\approx 10 \%$ for the dynamic moduli data and $\approx 15 \%$ for the crossover strain. The dashed lines indicate a power-law fits to the data. 


\section{(C) Irreversibility of temperature-induced structural changes in $\mathrm{Ca}(\mathrm{OH})_{2}$ suspension}

Figure S7a displays the flow curves procured from the initial shear rate sweep at $25^{\circ} \mathrm{C}$ and the second shear rate sweep performed at $25^{\circ} \mathrm{C}$ following the measurements at $25^{\circ} \mathrm{C}, 50^{\circ} \mathrm{C}$ and $75^{\circ} \mathrm{C}$ in order to investigate the irreversible modifications in the rheological response due to the imposed temperature variations. The flow curve mismatch between two measurements suggests the irreversibility of temperature-induced structural changes in $\mathrm{Ca}(\mathrm{OH}) 2$ suspensions. Figure $\mathrm{S} 7 \mathrm{~b}$ shows the variation in the crossover energy of the suspensions at $25^{\circ} \mathrm{C}$ before and after the temperature perturbations.

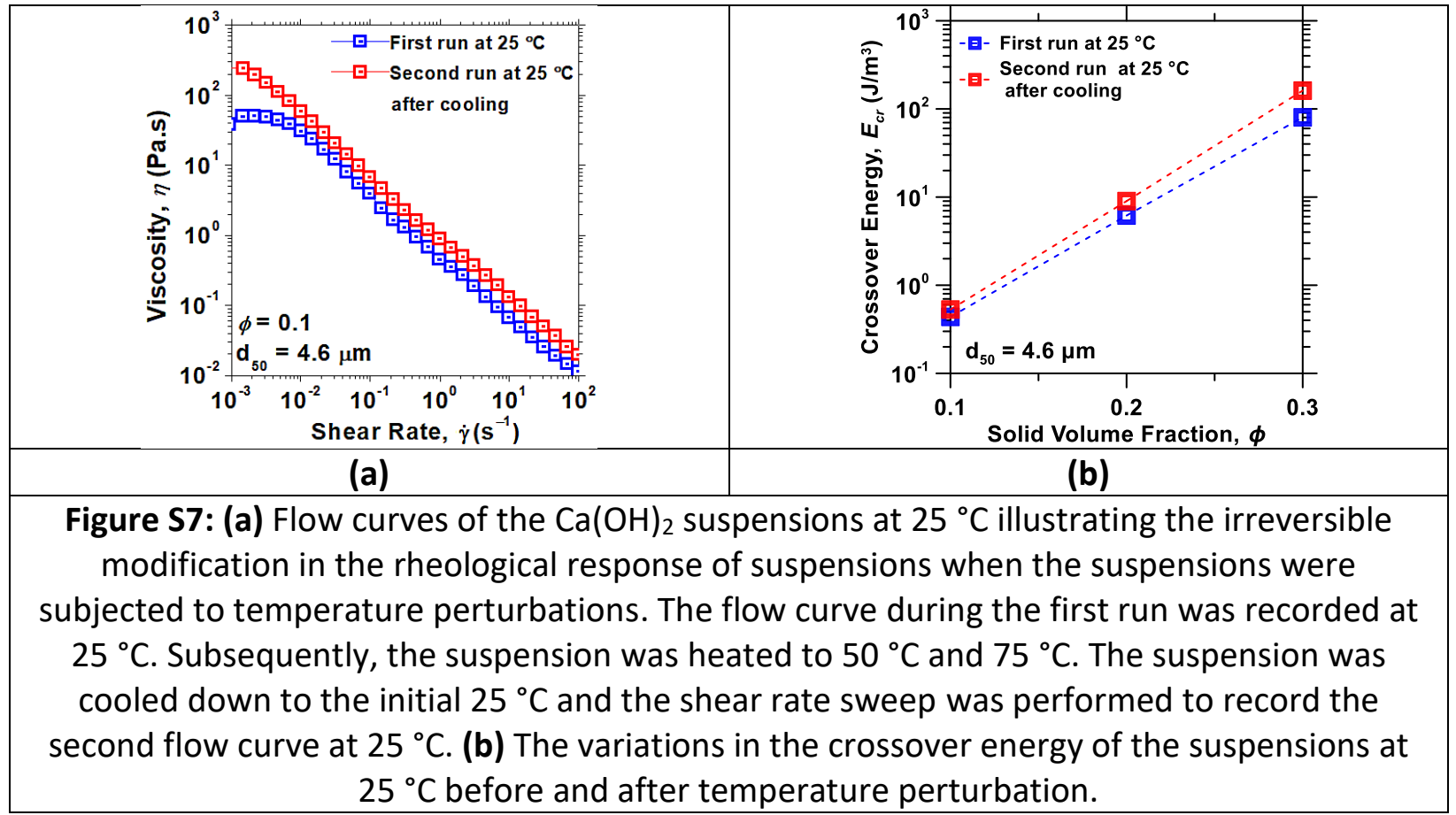

(D) Temperature-induced changes in $\mathrm{pH}$ and ionic strength of saturated $\mathrm{Ca}(\mathrm{OH})_{2}$ solution Due to the decrease in solubility of $\mathrm{Ca}(\mathrm{OH})_{2}$ with the increase in temperature, the saturated $\mathrm{Ca}(\mathrm{OH})_{2}$ solution exhibits a decrease in $\mathrm{pH}$ and ionic strength (Figure S8). As ionic strength decreases with increasing temperature, the Debye length shows a marginal increase (Figure $\mathrm{s} 8 \mathrm{~b})$. 


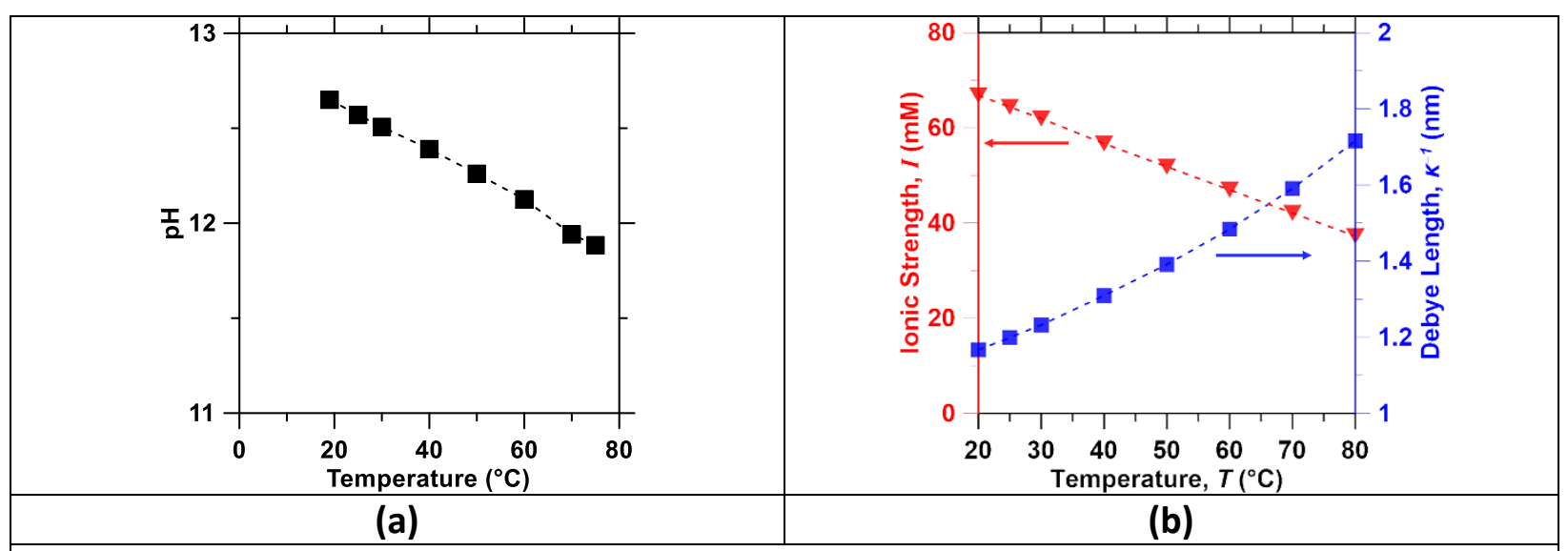

Figure S8: (a) The variations in $\mathrm{pH}$ of saturated $\mathrm{Ca}(\mathrm{OH})_{2}$ solution as a function of the temperature. (b) The ionic strength of the saturated $\mathrm{Ca}(\mathrm{OH})_{2}$ solution as a function of the temperature. The ionic strength is estimated based on solubility data provided in Bates et al. ${ }^{1}$

\section{(E) Temperature-dependent viscosity of quartz suspensions in $\mathrm{Ca}(\mathrm{OH})_{2}$ solution}

Figure S10a shows the variation in the zeta potential of quartz as a function of the ionic strength of the $\mathrm{Ca}(\mathrm{OH})_{2}$ solution. Figure S10b shows the Arrhenius plots of viscosity for quartz suspensions $(\phi=0.3)$ in DI water as well as in $\mathrm{Ca}(\mathrm{OH})_{2}$ solutions with varying ionic strength. Figure S10c illustrates the Arrhenius plots of viscosity for quartz suspensions $(\phi=0.3)$ that were prepared in $\mathrm{NaOH}, \mathrm{Ca}(\mathrm{OH})_{2}$ and $\mathrm{CaCl}_{2}$ solutions featuring identical ionic strength $(I \sim 60$ $\mathrm{mM})$.

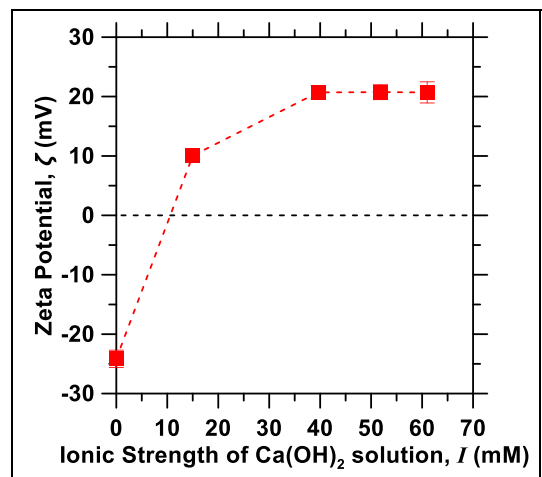

(a)

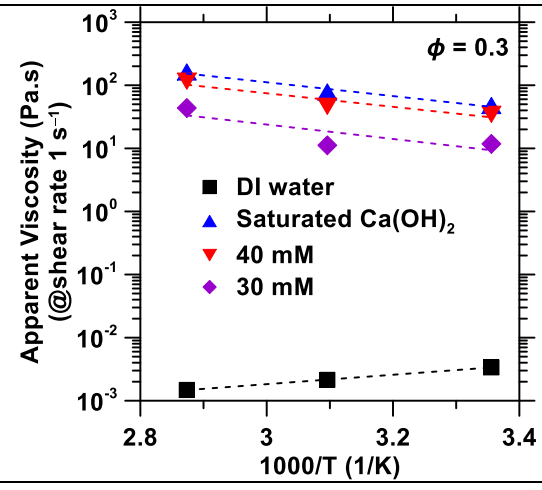

(b)

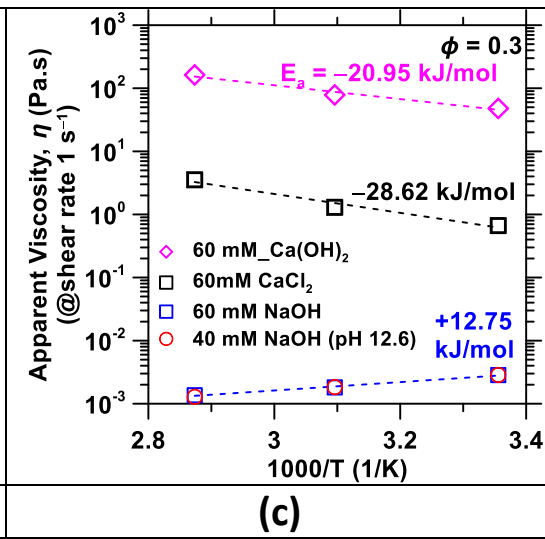

(c)

Figure S9: (a) The variations in the zeta potential of quartz particles suspended in $\mathrm{Ca}(\mathrm{OH})_{2}$ solution as a function of the ionic strength, illustrating the surface charge reversal of quartz particles. The error bars are based on the six replicate measurements. (b) Arrhenius plots of viscosity for quartz suspensions $(\phi=0.3)$ in DI water as well as in $\mathrm{Ca}(\mathrm{OH})_{2}$ solutions with varying ionic strengths. The dashed lines are the data fit using an Arrhenius equation; (c) Arrhenius plots of viscosity for quartz suspensions $(\phi=0.3)$ in $\mathrm{NaOH}, \mathrm{Ca}(\mathrm{OH})_{2}$ and $\mathrm{CaCl}_{2}$ solutions featuring identical ionic strength $(I \sim 60 \mathrm{mM})$. It also shows the Arrhenius plots of quartz suspension in $\mathrm{NaOH}$ solution having the identical $\mathrm{pH}(\mathrm{pH} \sim 12.6)$ as that of the saturated $\mathrm{Ca}(\mathrm{OH})_{2}$ solution. The dashed lines are the data fit using an Arrhenius equation 


\section{References}

(1) Bates, R. G.; Bower, V. E.; Smith, E. R. Calcium Hydroxide as a Highly Alkaline PH Standard. J. Res. Natl. Bur. Stand. (1934). 1956, 56 (6), 305-312.

https://doi.org/10.6028/jres.056.040. 